\title{
DESVENDANDO O PERFIL DOS GASTOS EDUCACIONAIS DOS MUNICÍPIOS BRASILEIROS
}

\author{
RaImundo Luiz Silva ARaújo*
}

\begin{abstract}
RESUMO: Este artigo sistematiza os resultados da pesquisa "Perfil dos Gastos Educacionais nos Municípios Brasileiros - ano base 2009", desenvolvida pela Undime. A pesquisa foi motivada pela constatação de que as informações disponíveis sobre os custos da educação municipal estavam imprecisas. A pesquisa comprovou a fragilidade dos indicadores sistematizados pelo Siope, mostrando que há uma subdeclaração dos gastos municipais em educação infantil e educação de jovens e adultos. Demonstrou ainda que os fatores de ponderação utilizados pelo Fundeb estão distantes dos valores efetivamente praticados, especialmente para creches. Uma das descobertas é que a política de fundos não tem conseguido ser eficiente na diminuição da desigualdade territorial. O estudo comprova a distância entre o padrão mínimo de qualidade instituído pelo Conselho Nacional de Educação e os gastos efetivados pelos municípios nordestinos.
\end{abstract}

Palavras-chave: Financiamento da educação. Gasto educacional. Fundeb. Siope.

\section{UNVEILING THE BRAZILIAN MUNICIPALITIES' PROFILE OF EDUCATIONAL COSTS}

\begin{abstract}
This article synthesizes the results of the survey "Profile of Educational Expenditures in Brazilian Municipalities - 2009 Base Year", developed by the Association of Municipal Education Directors. The research was motivated by the fact that the available information on the costs of municipal education was inaccurate. The research proved the fragility of the indicators systematized by Siope, showing that there is an underreporting of municipal spending on early childhood education and education for youth and adults. It also showed that the weighting factors used by Fundeb are distant from the values effectively practiced, especially for day care center. One finding is that the Fundeb has failed to be effective in reducing regional inequality. It also proves the distance between the minimum quality standard established by the National Council of Education and the effective spending by municipalities in the Northeast.
\end{abstract}

Key words: Education funding. Education spending. Fundeb. Siope.

\footnotetext{
* Doutorando na Faculdade de Educação da Universidade de São Paulo (USP). E-mail: rluiz_araujo@ yahoo.com.br
} 


\title{
DÉMÊLER LE PROFIL DES FRAIS D'ENSEIGNEMENT DES MUNICIPALITÉS BRÉSILIENNES
}

\begin{abstract}
RÉSUMÉ: Cet article synthétise les résultats de l'enquête "Profil des dépenses d'éducation dans les municipalités brésiliennes - 2009 année de base", développée par l'Association des directeurs municipaux de l'éducation. La recherche a été motivée par le fait que les informations disponibles sur les coûts de l'éducation municipale étaient inexactes. La recherche a prouvé la fragilité des indicateurs systématisés par Siope, montrant qu'il y a une sous-déclaration des dépenses municipales consacrées à l'éducation de la petite enfance et l'éducation pour les jeunes et les adultes. Elle a également montré que les facteurs de pondération utilisés par Fundeb sont éloignés des valeurs effectivement pratiquées, en particulier pour les garderies. Une constatation est que le Fundeb n'a pas réussi à être efficace dans la réduction des inégalités régionales. Cela prouve aussi la distance entre la norme de qualité minimum fixée par le Conseil national de l'éducation et les dépenses efficaces par les municipalités dans le Nord-Est.
\end{abstract}

Mots-clés: Financement de l'éducation. Les dépenses d'éducation. Fundeb. Siope.

\section{Introdução}

$\mathrm{E}$ ste artigo sistematiza os resultados da pesquisa "Perfil dos gastos educacionais nos municípios brasileiros - ano base 2009", desenvolvida pela União Nacional dos Dirigentes Municipais de Educação (Undime). ${ }^{1}$ A pesquisa foi motivada pela constatação de que as informações disponíveis sobre os custos da educação municipal estavam imprecisas. Esta imprecisão indicava uma possível subdeclaração dos dados da educação infantil e da educação de jovens e adultos coletados pelo Sistema de Informações sobre Orçamentos Públicos em Educação (Siope). ${ }^{2}$

Além da possível fragilidade dos dados, a pesquisa também se propôs a enfrentar o debate sobre outra grande lacuna na área de estudo. Desde a criação do Fundo de Manutenção e Desenvolvimento do Ensino Fundamental e de Valorização do Magistério (Fundef) e sua posterior substituição pelo Fundo de Manutenção e Desenvolvimento da Educação Básica e de Valorização dos Profissionais da Educação (Fundeb) que a redistribuição dos recursos é feita por meio de fatores de ponderação entre as etapas e modalidades. Há uma carência de pesquisas que balizem a distância real entre os custos de cada etapa e modalidade e que tenham como escopo um universo amostral com validade nacional.

A Lei n. 11.494/07 estabeleceu um intervalo máximo de $30 \%$ para mais ou para menos entre elas. A referida legislação, em seu artigo 13, inciso I, determina que a especificação das ponderações deva levar em consideração "a correspondência ao 
custo real da respectiva etapa e modalidade e tipo de estabelecimento de educação básica, segundo estudos de custo realizados e publicados pelo Inep". Porém, tal tarefa não foi executada até o momento.

A pesquisa também reuniu elementos para aprofundar o debate sobre o padrão mínimo de qualidade. Este conceito foi explicitado pelo inciso VII do artigo 206, da Constituição de 1988. Também no seu artigo 211, a Carta Magna, ao discorrer sobre a função redistributiva e supletiva da União em matéria educacional, estabelece que tal função deveria garantir uma equalização de oportunidades educacionais e um padrão mínimo de qualidade.

A necessidade de definição de um padrão mínimo de qualidade está presente na Lei de Diretrizes e Bases e estava nas preocupações do Plano Nacional de Educação, que teve sua vigência encerrada em dezembro de 2010. Ao ser regulamentada a Emenda Constitucional n. 53, o Legislativo deu prosseguimento à materialização dos objetivos constitucionais. No artigo 13 da Lei n. 11.494/2007 é dito que, entre as atribuições da Comissão Intergovernamental de Financiamento para a Educação Básica de Qualidade, estaria a tarefa de especificar anualmente as ponderações aplicáveis entre diferentes etapas, modalidades e tipos de estabelecimento de ensino da educação básica. Contudo, esse trabalho deveria ser subsidiado por estudos realizados pelo Instituto Nacional de Estudos e Pesquisas Educacionais Anísio Teixeira (Inep) sobre o custo real da respectiva etapa, modalidade e tipo de estabelecimento de educação básica.

A contribuição de materialização deste padrão utilizado pela pesquisa foi o esforço realizado pela Câmara de Educação Básica do Conselho Nacional de Educação (CEB/CNE), que aprovou, em 5 de maio de 2010, o Parecer n. 8/ 2010, tratando dos padrões mínimos de qualidade de ensino para a educação básica pública e estabelecendo as normas para a aplicação do inciso IX do artigo 4º da Lei n. 9.394/ 96. Para tanto, o Parecer incorporou o estudo do Custo Aluno-Qualidade Inicial (CAQi), desenvolvido pela Campanha Nacional pelo Direito à Educação. ${ }^{3}$

São necessários alguns esclarecimentos acerca dos conceitos envolvidos em pesquisa sobre gastos educacionais municipais e do estado da arte da produção acadêmica sobre o tema, mesmo que neste artigo não seja possível realizar exaustiva revisão bibliográfica.

O custo educacional refere-se aos recursos ou meios utilizados para a oferta do serviço educacional, expressos em valores monetários. Quando for descrito o custo por aluno efetivamente executado pelas redes municipais, estará sendo representada a totalidade das aplicações financeiras, seja aquilo que a literatura considera como custo direto (diretamente identificável com a unidade escolar), seja o denominado de custo indireto (atividades de suporte e de controle educacional que apoiam o conjunto de escolas). 
Ao comparar o custo por aluno efetivamente realizado com o conceito de custo aluno-qualidade, nota-se que este último representa o valor, por aluno, no período de um ano, dos recursos necessários ou desejáveis para um ensino de qualidade, conforme metodologia elaborada pela Campanha Nacional pelo Direito à Educação.

Este procedimento não significa que há discordância com a preocupação conceitual expressa em Sales e Silva (2009), quando afirmam que:

(...) numa perspectiva contábil, despesas e gastos são usualmente apresentados como sinônimos de custo, porém, numa perspectiva econômica, despesas e gastos se confundem com desembolso, e custo, ao contrário, não necessariamente existe mediante desembolso financeiro. Ou seja, custo significa todo e qualquer sacrifício feito para produzir um determinado bem ou serviço. Logo, o conceito de custo é mais amplo que os conceitos de despesas ou gastos. (Sales \& Silva, 2009, p. 700)

É preciso sempre lembrar que o Brasil convive com custos educacionais diferenciados, associados ao perfil de arrecadação dos estados e municípios, à quantidade de crianças e jovens atendidos em suas respectivas redes e ao quantitativo de recursos complementados pela União por meio do Fundeb, a depender do estado.

No âmbito do Fundeb, os valores encontrados anualmente em cada fundo estadual não representam a totalidade do custo educacional efetivo, visto que nem todos os recursos educacionais estão vinculados ao Fundo. Nos municípios, os 25\% dos impostos de arrecadação própria que devem ser investidos na educação não estão incorporados no Fundeb. Há, também, os 5\% restantes da cesta de impostos que compõe o Fundeb. Afora estes valores obrigatórios, existem os recursos da cota-parte do salário-educação e os recebidos pela via do repasse automático ou voluntário do Fundo Nacional de Desenvolvimento da Educação (FNDE), especialmente aqueles referentes ao Programa Nacional de Transporte Escolar (Pnate), ao Programa Dinheiro Direto na Escola (PDDE) e ao Programa Nacional de Alimentação Escolar (PNAE).

A soma de todos estes recursos (Fundeb, recursos próprios, transferências) dividida pela matrícula efetiva da rede escolar permite o cálculo do efetivo custo por aluno de cada ente federado, posteriormente sendo diferenciado por etapa e modalidade. O custo por aluno levantado pela Pesquisa da Undime não levou em consideração o denominado custo privado, o qual inclui "as despesas feitas por estudantes ou suas famílias com taxas, livros, uniformes e transporte entre a casa e a escola, assim como o que quer que o aluno tenha sacrificado em termos de remuneração, a fim de poder estudar" (Brasil/Inep, 2004, p. 26).

Em termos de esforço do governo federal para coletar, processar, disseminar e tornar públicas as informações referentes aos orçamentos de educação dos estados, do Distrito Federal e dos municípios, cabe registrar a criação do Sistema de Informações sobre Orçamentos Públicos em Educação (Siope), instituído pelo FNDE. Devido ao 
Siope, desde 2006, é possível ter uma base nacional de dados sobre a aplicação da receita vinculada à educação.

Não existem, ainda, muitas pesquisas sobre o custo por aluno da educação básica, mas algum esforço tem sido feito pelos meios acadêmicos para suprir esta deficiência.

A pesquisa intitulada "O custo-aluno no ensino fundamental público no Brasil: resultados de uma pesquisa de campo" foi apresentada em julho de 2001 por Miguel Bacic e José Carpintéro. O trabalho foi o produto de uma amostra em 103 unidades escolares de sete aglomerações urbanas metropolitanas (Goiânia, Belém, Salvador, Belo Horizonte, São Paulo, Campinas e Curitiba), abrangendo escolas estaduais e municipais.

Estes dois pesquisadores advertiam para o fato de que a criação do Fundo de Manutenção e Desenvolvimento do Ensino Fundamental e de Valorização do Magistério (Fundef) - Lei n. 9.424/96 - demonstrou a necessidade de definição de um custo por aluno, pois a legislação do Fundo estabelecia que a "distribuição dos recursos deveria passar a considerar a diferenciação de custo por aluno, segundo níveis de ensino e tipos de estabelecimento, adotando-se metodologia de cálculo e as correspondentes ponderações de acordo com seus diferentes componentes" (Carpintéro \& Bacic, 2001, p. 3).

Os autores encontraram grandes diferenças entre o custo por aluno nas regiões estudadas e isso poderia ser explicado por diversos fatores: a) diferenças no salário docente (principal componente, no geral, do custo por aluno); b) a relação horas/docente por aluno; c) a importância do custo salarial do pessoal sem atividade em sala de aula e d) os custos de estrutura.

Um dado importante encontrado na referida pesquisa é que os salários (incluindo os encargos sociais) representam cerca de $85 \%$ deste custo, com oscilações nas diferentes regiões pesquisadas entre $79,84 \%$ e $90,18 \%$.

Em 2004, o Inep - consorciado com instituições federais de ensino superior realizou pesquisa acerca do custo por aluno e das condições de oferta educacional em escolas públicas reconhecidas por conviverem com indicadores positivos de desempenho e infraestrutura. Pelas próprias características da amostra, esta pesquisa não foi representativa do real custo por aluno da rede pública, mas trouxe elementos interessantes acerca dos efeitos positivos da existência de um padrão mínimo de qualidade.

Em janeiro de 2006, durante a tramitação do Fundeb, a Confederação Nacional dos Municípios (CNM) se consorciou com a Faculdade de Educação da Universidade Federal do Rio Grande do Sul (UFRGS) para realizar uma pesquisa sobre o 
tema do custo por aluno. Coordenaram a pesquisa Eduardo Stranz (CNM), Maria Goreti Machado (UFRGS) e Nalú Farenzana (UFRGS).

A partir de um universo amostral de setecentas escolas públicas municipais, distribuídas em 185 localidades, a pesquisa verificou os custos diretos de 196 escolas, distribuídas em 56 municípios de 16 estados, representando 32,4\% de respostas. O relatório alerta para o fato de que as dificuldades de coleta configuraram "uma amostra não equilibrada em termos de número proporcional de escolas por estado ou por região". Assim,

As estimativas de médias nacionais, estaduais e municipais de custo-aluno/ano levantadas por essa pesquisa permitem, pois, levantar ou confirmar algumas tendências e situações, desde que balizadas pela compreensão de que está muito longe de dar conta da diversidade de oferta e de organização escolar existente no Brasil. (CNM, 2006, p. 15)

Mesmo com as ressalvas anteriores, o estudo chegou a algumas conclusões. Evidenciou-se significativa dispersão dos valores de custo entre os estados, entre municípios de um mesmo estado ou entre escolas de um mesmo município. Os custos médios por estado também revelam o corte regional. As ponderações dos valores de custo da creche, da pré-escola, do ensino fundamental/anos finais, da EJA/ensino fundamental e da educação especial em relação ao ensino fundamental/anos iniciais, considerando a amostra do estudo, indicam o valor relativamente maior da creche e da educação especial; para os segmentos da pré-escola, ensino fundamental/anos finais e EJA/ensino fundamental, as ponderações indicam que é questionável propor ou concluir pelo estabelecimento ou ocorrência mais generalizada de pesos diferenciados.

Para os pesquisadores, a diferença regional no custo educacional, mais uma vez confirmada, leva a assertiva de que:

(...) é a situação que demonstra o imprescindível papel da União na equalização de oportunidades educacionais, destacando-se a necessidade e a urgência de que o regime de colaboração no financiamento da educação conte com aporte significativo de recursos do governo federal a ser transferido aos estados e municípios. (Idem, ibid., p. 24)

Ainda em 2006, foi desenvolvida outra pesquisa, coordenada por Luis Carlos Sales e Magna Jovita Silva, intitulada "O financiamento da educação pública municipal de Teresina: o custo-aluno/ano". O objetivo da pesquisa foi o de identificar o custo por aluno em 17 escolas municipais de Teresina, verificando somente o custo direto e separando a sua origem.

No estudo, os autores encontraram um custo direto com pessoal de 63,6\%, bem inferior ao verificado em outros trabalhos. Detectaram, também, que o Fundef 
cobria apenas metade do custo direto das escolas pesquisadas. A segunda fonte principal foram recursos próprios da prefeitura, sendo pouco significativo o aporte recebido pela via do FNDE.

\section{Uma contribuição ao desvendamento}

Para se construir a amostra da pesquisa, as bases de dados foram obtidas do Siope, fornecido pelo FNDE, e do Censo Escolar da Educação Básica do Brasil. No caso do Siope, as informações são aquelas referentes às despesas declaradas pelos gestores em 2009 e publicadas em 2010.

Os dados do Siope serviram de base para construir estratificação de municípios pelo perfil de suas despesas educacionais. No caso do Censo Escolar, para construir a amostra foi utilizado o número de alunos, de escolas públicas municipais, matriculados por etapa e modalidade, no ano de 2008, pois são as matrículas correspondentes às despesas executadas no ano de 2009. Contudo, para encontrar o custo por aluno de 2009 foram utilizados os dados censitários escolares de 2009.

Após ter sido construída uma amostra de mil municípios, realizada a coleta de dados e, sobre os formulários entregues, ter sido feita uma verificação de consistência, foram validados 224 formulários, ou seja, 22,4\% do universo efetivo pesquisado. A distribuição das respostas está demonstrada na tabela 1.

A quantidade de formulários respondidos e consistentes foi equivalente ao alcançado em outras pesquisas amostrais sobre custo por aluno. Porém, em alguns estados a quantidade de respostas foi insatisfatória, prejudicando o objetivo de desdobrar os resultados da pesquisa por unidades federadas (UF). Foram obtidas respostas de 25 estados. A única exceção foi o Amapá. Destaque para o resultado abaixo da expectativa alcançado nos estados do Amazonas (8,3\%), Maranhão (2,5\%), Paraíba $(4,8 \%)$ e Sergipe $(6,6 \%)$.

Como a pesquisa pretendia observar possíveis fragilidades dos dados disponíveis nos sistemas existentes, antes de descrever os resultados encontrados é necessário apresentar os valores por aluno coletados pelo Siope em 2009 e válidos para o Brasil, os quais estão descritos na tabela 2.

Uma primeira leitura dos valores por aluno da educação municipal, registrados pelo Siope, já aponta para possíveis distorções, seja pelo valor da educação infantil aparecer menor do que o ensino fundamental, seja pelo valor residual registrado para a educação de jovens e adultos. Não é um resultado esperado que, em alguma etapa e modalidade, os valores médios sejam muito inferiores aos valores por aluno distribuídos pelo Fundeb no respectivo fundo estadual. Assim, um valor 
para as matrículas de educação de jovens e adultos muito mais baixo do que o valor distribuído para os nove fundos estaduais mais pobres demonstra a existência de problemas nos dados do Siope.

A primeira evidência que pode ser extraída do banco de dados da pesquisa é sobre o valor por aluno, por etapa e modalidade estudadas. As informações encontradas, válidas para o Brasil, estão demonstradas na tabela 3.

Para facilitar a comparação dos resultados da pesquisa com os dados do Siope, foram agregados os dados de educação infantil e ensino fundamental. Estes dados agregados representam valores médios da totalidade dos recursos declarados pelos municípios, divididos pela respectiva matrícula. ${ }^{4}$

Comparando estes resultados com os valores médios nacionais registrados pelos municípios junto ao Siope, foi possível comprovar a existência de significativa distorção entre as duas declarações. Há fortes evidências de que ocorreu no Siope uma declaração a maior no ensino fundamental, em detrimento da educação infantil e da educação de jovens e adultos. A tabela 4 evidencia que os valores atribuídos para a educação infantil pelos municípios no Siope são $29,7 \%$ menores do que os verificados na pesquisa. No caso da educação de jovens e adultos, o valor do Siope é 92,6\% menor do que o declarado nos formulários da pesquisa.

Estes números reforçam a premissa de que está ocorrendo uma declaração a maior nos dados sobre o ensino fundamental. A análise dos formulários da pesquisa e os contatos com os dirigentes educacionais de municípios que participaram dela possibilitam o levantamento de algumas hipóteses explicativas:

1. Há dificuldade de separação dos gastos efetuados entre as etapas e modalidades, sendo que muitos orçamentos municipais continuam estruturados na lógica vivenciada pro dez anos no Fundef, onde a prioridade contábil era a declaração dos gastos do ensino fundamental.

2. Os dados municipais que são fornecidos ao Siope não são sistematizados nem inseridos por dirigentes educacionais. Em pequenos municípios, são os escritórios de contabilidade que realizam a tarefa. Em municípios médios e grandes, são as secretarias de finanças que o fazem.

3. Não há preocupação em desagregar os gastos na peça orçamentária e a consequência é a falta de transparência dos dados registrados na contabilidade e depois fornecidos ao Tesouro Nacional e ao Siope.

4. Em muitos municípios, nem mesmo a folha de pagamento da educação infantil e da educação de jovens e adultos é lançada de forma desagregada da folha do ensino fundamental. 
Também foi possível desdobrar as informações obtidas pela pesquisa por região. Na tabela 5 são apresentadas informações de cada uma das regiões. Apenas as informações sobre "creche" e "educação de jovens e adultos" da região Norte não foram aceitas, por estarem acima da margem de segurança estabelecida.

Os dados confirmam a existência de forte desigualdade entre as regiões. $\mathrm{O}$ valor médio encontrado em creches no Nordeste representa apenas 36,5\% da média nacional. Por outro lado, o valor encontrado no Sudeste é 4,4 vezes maior do que o praticado no Nordeste e 1,6 vezes maior do que a média nacional. Mesmo no ensino fundamental, que possui uma base redistributiva pela via da política de fundos há 15 anos, a diferença entre Sudeste e Nordeste é de quase duas vezes $(1,91)$.

A constatação de desigualdades regionais é a confirmação de que a capacidade de arrecadação própria dos municípios das regiões Norte e Nordeste é muito inferior à registrada nos municípios das regiões Sudeste e Sul, tornando-os mais dependentes das receitas transferidas. Como ilustrarei mais adiante, a persistência das desigualdades pode mostrar os limites da capacidade do formato atual da política de fundos de reverter este quadro, mesmo que tenhamos concordância com a afirmação de que, "em estados federativos que centralizem a formulação de políticas executadas pelas unidades constituintes e que contem com um sistema jurisdicional de transferências, é possível encontrar redução das desigualdades territoriais" (Arretche, 2010, p. 593).

\section{Ponderações distorcidas}

Utilizando as séries iniciais do ensino fundamental como indexador, formato consagrado pela política de fundos para construir as planilhas de redistribuição dos recursos, a pesquisa identificou as diferenças reais médias entre as etapas e modalidades, conforme descrito na tabela 6 . Destaque para a diferenciação de 1,83 de creches para as séries iniciais e o valor de 0,67 encontrado na relação entre educação de jovens e adultos e o indexador.

Esta certamente é uma importante contribuição deste trabalho, pois lança luz sobre uma das áreas com menor produção teórica, que tem consumido boa parte do tempo de debate entre os entes federados e possui alta incidência no direcionamento que as políticas públicas dão para os gestores, no que diz respeito à oferta de matrículas em cada etapa e modalidade.

Sendo um componente importante da política de redistribuição de recursos educacionais pela via da política de fundos, a justeza dos percentuais dos fatores de ponderação aplicados é questionada pelos dados coletados pela pesquisa. A tabela 7 permite comparar os fatores aplicados em 2009 e 2011 pelo Fundeb e aqueles efetivamente realizados pelos municípios. 
O fator de ponderação utilizado pelo Fundeb para a remuneração das matrículas em creche representou, em 2009, apenas $60,1 \%$ do que efetivamente este serviço custou para a municipalidade. No caso da pré-escola, o valor repassado representou $85,1 \%$ do efetivado. Somente o valor da educação de jovens e adultos se mostrou acima do efetivado (19\% acima).

A diferenciação aplicada em 2011 diminui a distância apurada pela pesquisa, tornando equilibrada a remuneração da pré-escola e diminuindo a defasagem da creche $(65,6 \%$ do valor), mas ainda representa um ajuste pouco efetivo diante dos dados detectados pela pesquisa.

Esta informação é revestida de grande importância para o efeito indutor que os fatores de ponderação possuem: quanto mais distante do gasto real, menos estimulador do aumento da oferta e mais indutor de formas precárias de oferecimento dos serviços.

\section{Elementos de desigualdade}

Foram selecionados, pelo grau de confiabilidade de seus dados, quatro estados representativos (Santa Catarina, São Paulo, Mato Grosso do Sul e Ceará) de cada uma das regiões. Pelos motivos descritos anteriormente, não foi possível selecionar nenhum estado da região Norte. A diferenciação regional é bastante significativa, como pode ser verificado no gráfico 1 .

Considerando a rede municipal do Ceará como indexador, estado que, desde o início do Fundeb, tem sido contemplado com auxílio financeiro da União, fica nítida a desigualdade territorial em todas as etapas e modalidades. Um aluno matriculado em uma creche paulista teve disponível, em 2009, 3,53 vezes mais recursos e um aluno da pré-escola teve 3,61 mais recursos que um aluno cearense. Distância um pouco menor, mas significativa, também é encontrada entre os alunos cearenses e os catarinenses. Em Santa Catarina, um aluno de creche e de pré-escola recebeu, respectivamente, 2,72 e 2,70 vezes o valor aferido no Ceará.

Esta distorção está presente em menor proporção mesmo em etapas que estão praticamente universalizadas. A diferença entre o recurso disponível de alunos nas séries iniciais do ensino fundamental foi de 1,64 (Santa Catarina), 1,81 (São Paulo) e 1,65 (Mato Grosso do Sul).

A pesquisa comparou estas diferenciações com os dados de diferenciação regional descritos pelos valores do Fundeb. A tabela 8 mostra que a distância efetiva entre estes estados é maior do que a que seria esperada, caso fossem considerados apenas os números dos recursos redistribuídos pelo Fundeb em cada estado. 
Uma explicação para esta diferença é que a existência de recursos próprios nos municípios de Santa Catarina (e, provavelmente, nos demais estados da região Sul) e em São Paulo (e, provavelmente, nos demais estados da região Sudeste) é determinante para manter uma diferenciação mais elevada no atendimento encontrado no Ceará (e, provavelmente, nos demais estados da região Nordeste).

Um caminho para comprovar a afirmação de que os recursos próprios existentes nas regiões Sul e Sudeste explicam esta diferença é comparar o quanto dos recursos aplicados efetivamente em 2009 foram cobertos pelos valores repassados pelo Fundeb. O gráfico 2 faz este exercício, tendo por base os gastos efetivados em 2009 em creches.

O recurso transferido pelo Fundeb representa $66,5 \%$ do recurso efetivamente gasto no atendimento em creches no Ceará e 60,3\% no Mato Grosso do Sul, mas representa apenas 32,1\% do recurso utilizado em santa Catarina e 30,3\% do recurso aplicado em São Paulo.

Assim, estados das regiões com menor capacidade de geração de recursos próprios ou de outras fontes adicionais de financiamento educacional conviverão com valores inferiores por aluno. A possibilidade de redução desta desigualdade, que está ancorada no perfil do desenvolvimento regional e na distribuição dos recursos tributários no país, repousará na capacidade da política redistributiva (neste caso, o Fundeb) de minimizar seus efeitos.

Os resultados da pesquisa problematizam a capacidade de reduzir desigualdades que uma política de fundos estaduais possui.

Apesar de ilustrarmos com os números de creches, resultados semelhantes foram encontrados nas demais etapas e modalidades contempladas pela pesquisa.

\section{Um padrão mínimo ainda distante}

A pesquisa permite verificar a distância entre os valores propostos pelo Parecer do CNE acerca do CAQi e os efetivados pelos municípios.

Os valores calculados pelo Parecer possuem duas diferenças que devem ser ressaltadas antes da realização de qualquer comparação. O CAQi introduz importante distinção entre valores para matrículas urbanas e rurais, dado não analisado pela presente pesquisa. Por isso, a comparação feita entre "séries iniciais" da pesquisa e "séries iniciais urbanas" do CAQi deve ser lida com as devidas ressalvas. Enquanto o valor das séries iniciais urbanas deste custo representa 14,3\% do PIB per capita, o valor para as matrículas rurais é de 26,9\%. O CAQi também não apresenta valores para a educação de jovens e adultos. 
A tabela 9 compara os valores do Parecer do CNE com os dados aferidos pela pesquisa na região Nordeste. Esta escolha é coerente com o princípio de que o CAQi seria um patamar mínimo a ser alcançado por todos os municípios e estados brasileiros. As regiões Norte e Nordeste são detentoras dos indicadores educacionais mais precários e aparecem na pesquisa com os valores por aluno de menor tamanho. Como os dados da região Norte não permitiram utilizar dados de creches e educação de jovens e adultos, só foi possível comparar o CAQi com o Nordeste. Contudo, dos nove estados contemplados por ajuda financeira da União no Fundeb, sete se localizam nesta região, o que torna esta ajuda bastante representativa de municípios que seriam alvo de uma elevação do padrão de qualidade.

A comparação realizada confirma as afirmações sobre a desigualdade regional. Na região Nordeste os municípios aplicaram em 2009, no atendimento em creche, apenas $29,1 \%$ do que seria necessário para estabelecer um padrão mínimo de qualidade no formato proposto pelo CAQi. Na pré-escola, o esforço dos municípios nordestinos alcançou 60,6\%.

O dado encontrado pela Pesquisa na região Nordeste para as séries iniciais e finais é próximo dos valores do CAQi, mas este resultado está associado à impossibilidade de aplicar a diferenciação feita pelo Parecer do CNE entre matrículas urbanas e rurais.

Por fim, considerando que o CAQi é indexado pelo PIB per capita e 2009 (ano base do presente estudo) foi um ano de baixo crescimento econômico, decorrente da crise econômica mundial, estima-se que a distância entre o valor mínimo determinado por este indicador e o investimento realizado nas regiões Nordeste e Norte do país tenha aumentado nos anos seguintes.

A distância entre o gasto real na região Nordeste e o gasto pretendido pelo Parecer do CNE realça a importância do estabelecimento de políticas públicas diferenciadas para possibilitar a elevação do padrão de atendimento presente nos municípios mais pobres do país.

\section{Pequena contribuição ao debate}

O esforço desenvolvido por uma entidade da sociedade civil para identificar o gasto real educacional dos municípios brasileiros representa uma contribuição relevante e um alerta. A contribuição é em aumentar o acúmulo teórico sobre o custo educacional em nosso país, estimulando novas pesquisas e reflexões. $\mathrm{O}$ alerta que a pesquisa indiretamente faz é que há fragilidade nos dados que são utilizados para formatar importantes políticas públicas nacionais.

A realização de pesquisas acadêmicas sobre custo educacional e sobre o padrão mínimo de qualidade continua sendo uma necessidade urgente. Esta tarefa é, ao mesmo 
tempo, uma obrigação legal do governo federal e uma necessidade teórica para que nossas políticas públicas se tornem mais efetivas no combate às desigualdades territoriais.

É necessário reformar o modo de coleta de dados do Siope, aperfeiçoando o controle de qualidade dos dados declarados pelos gestores municipais. É muito importante reabrir o debate acerca dos fatores de ponderação vigentes no Fundeb, pois os mesmos são indutores de perfis de oferta dos serviços educacionais. E a definição legal de padrões mínimos de qualidade e sua operacionalização são exigências fundamentais para que a educação não reproduza as desigualdades territoriais existentes.

\section{Notas}

1. A Pesquisa foi coordenada pelo autor e desenvolvida pela União Nacional dos Dirigentes Municipais de Educação (Undime) e contou com apoio financeiro da Fundação Itaú Social e do Fundo das Nações Unidas para a Infância (Unicef). A pesquisa teve a duração de oito meses, desenvolvida de agosto de 2010 a fevereiro de 2011.

2. O Siope, sistema gerenciado pelo FNDE, coleta dados de receita e despesa dos municípios e estados brasileiros. O Sistema tem por objetivos "subsidiar a elaboração de políticas educacionais em todos os níveis de governo" e "produzir indicadores de eficiência e eficácia da despesa pública em educação". O nível de desagregação de etapas e modalidades da rede municipal de ensino é em educação infantil, ensino fundamental, educação de jovens e adultos e educação especial.

3. Para construir o estudo do CAQi, a Campanha desenvolveu pesquisas sobre qualidade na educação; discutiu o custo aluno-qualidade em oficinas realizadas no período de 2002 a 2005, reunindo, em intensos debates, especialistas, lideranças da sociedade civil e autoridades governamentais das esferas municipal, estadual e federal. Todo o debate foi sistematizado no livro Custo Aluno-Qualidade Inicial: rumo à educação pública de qualidade no Brasil, publicado em 2007.

4. A distribuição desigual das matrículas de creches, estando concentrada nas regiões Sul e Sudeste, permitiu encontrar valores médios bem maiores do que o verificado quando se agrega seus dados com os de pré-escolas, estes com distribuição mais equilibrada entre as regiões.

\section{Referências}

ARRETCHE, M. Federalismo e igualdade territorial: uma contradição em termos. Revista de Ciências Sociais, Rio de Janeiro, v. 53, n. 3, p. 587-620, 2010.

BRASIL. Constituição (1988). Constituição da República Federativa do Brasil. Brasília, DF: Senado Federal, 1988.

BRASIL. Lei n. 9.394, de 20 de dezembro de 1996. Estabelece as Diretrizes e Bases da Educação Nacional. Diário Oficial da União, Brasília, DF, 23 dez. 1996. Disponível em: $<$ http://migre.me/8agGu >

BRASIL. Lei n. 10.172, de 9 de janeiro de 2001. Aprova o Plano Nacional de Educação e dá outras providencias. Diário Oficial da União, Brasília, DF, 10 jan. 2001. Disponível em: $<$ http://migre.me/8agHw $>$ 
BRASIL. Lei n. 11.494, de 20 de junho de 2007. Regulamenta o Fundo de Manutenção e Desenvolvimento da Educação Básica e de Valorização dos Profissionais da Educação - FUNDEB... Diário Oficial da União, Brasília, DF, 21 jun. 2007. Disponível em: $<$ http://migre.me/8agJ7>

BRASIL. Parecer CNE/CEB n. 8/2010, aprovado em 5 de maio de 2010. Estabelece normas para aplicação do inciso IX do artigo $4^{\circ}$ da Lei ${ }^{\circ}$ 9.394/96 (LDB), que trata dos padrões mínimos de qualidade de ensino para a Educação Básica pública. Disponível em: <http://migre.me/8agKk>

BRASIL. Ministério da Educação. Instituto Nacional de Estudos e Pesquisas Educacionais (INEP). Problematização da qualidade na pesquisa: levantamento do custo-aluno em escolas da educação básica que oferecem condições para oferta de um ensino de qualidade. Brasília, DF, 2004. (Relatório de pesquisa).

CARPINTÉRO, J.; BACIC, M. O custo-aluno no ensino fundamental público no Brasil: resultados de uma pesquisa de campo. Espanha: Universidade de Leon, 2001.

CARREIRA, D.; PINTO, J.M.R. Custo aluno-qualidade inicial: rumo à educação pública de qualidade no Brasil. São Paulo: Global; Campanha Nacional pelo Direito à Educação, 2007.

CONFEDERAÇÃO NACIONAL DOS MUNICÍPIOS (CNM). Um estudo do custo por aluno em escolas municipais brasileiras. Jan. 2008. (Relatório de pesquisa). Disponível em: <http://www.cnm.org.br >.

FARENZENA, N; VIEIRA, S. (Org.). Custos e condições de qualidade da educação em escolas públicas: aportes de estudos regionais. Brasília, DF: MEC/Inep, 2005.

SALES, L.C.; SILVA, M.J. O financiamento da educação pública municipal de Teresina: o custo-aluno/ano. Ensaio: Avaliação, Políticas Públicas Educacionais, Rio de Janeiro, v. 17, n. 65, p. 695-718, out./dez. 2009.

UNIÃO NACIONAL DOS DIRIGENTES MUNICIPAIS DE EDUCAÇÃO (UNDIME). Perfil dos gastos educacionais nos municípios brasileiros: ano base 2009. Brasília, DF, 2012. (Relatório de pesquisa). Disponível em: <http://tinyurl.com/6wnjmsw $>$. Acesso em: fev. 2012.

Recebido em 6 de março de 2012.

Aprovado em 17 de outubro de 2012. 
ANEXOS

\section{Tabela 1}

Municípios respondentes por região

\begin{tabular}{l|c|c|c|c}
\hline \multicolumn{1}{c|}{ Região } & $\begin{array}{c}\text { Amostra } \\
\text { inicial }\end{array}$ & Amostra final & Diferença & $\begin{array}{c}\text { Cobertura } \\
\mathbf{( \% )}\end{array}$ \\
\hline Norte & 87 & 18 & 69 & $20,69 \%$ \\
Nordeste & 328 & 46 & 282 & $14,02 \%$ \\
Sudeste & 290 & 73 & 217 & $25,17 \%$ \\
Sul & 211 & 64 & 147 & $30,33 \%$ \\
Centro-Oeste & 84 & 23 & 61 & $27,38 \%$ \\
Total & 1000 & 224 & 776 & $22,4 \%$ \\
\hline
\end{tabular}

Fonte: Banco de dados da pesquisa "Perfil dos gastos educacionais nos municípios brasileiros - ano base: 2009" (Undime).

\section{Tabela 2}

Valor por aluno registrados no Siope - Brasil (2009)

\begin{tabular}{lc}
\hline \multicolumn{1}{c}{ Etapa ou modalidade } & $\begin{array}{c}\text { Custo per capita } \\
\text { (R\$) }\end{array}$ \\
\hline Educação Infantil & $2.195,40$ \\
Ensino Fundamental & $3.047,00$ \\
Educação de Jovens e Adultos (EJA) & 140,10 \\
\hline
\end{tabular}

Fonte: Banco de dados Siope 2009 (FNDE). Tabulação própria.

Tabela 3

Estimativa de valor por aluno das redes municipais - Brasil (2009)

\begin{tabular}{lccc}
\hline Etapa ou modalidade & $\begin{array}{c}\text { Custo per capita } \\
\text { (R\$) }\end{array}$ & $\begin{array}{c}\text { Erro padrão } \\
\text { (R\$) }\end{array}$ & $\begin{array}{c}\text { Coeficiente de } \\
\text { Variação }\end{array}$ \\
\hline Creche & $5.144,09$ & $1.087,09$ & .21 \\
Pré-Escola & $2.647,10$ & 262,44 & .10 \\
Educação Infantil & $3.122,36$ & 383,93 & .12 \\
Fundamental Inicial & $2.815,46$ & 183,04 & .07 \\
Fundamental Final & $3.134,38$ & 270,42 & .09 \\
Ensino Fundamental & $2.937,65$ & 214,31 & .07 \\
EJA & $1.881,95$ & 266,20 & .14 \\
\hline
\end{tabular}

Fonte: Banco de dados da pesquisa "Perfil dos gastos educacionais nos municípios brasileiros - ano base: 2009" (Undime). 


\section{Tabela 4}

Diferença entre dados da Pesquisa Undime e do Siope - Brasil (2009)

\begin{tabular}{lccc}
\hline Fonte & $\begin{array}{c}\text { Educação } \\
\text { Infantil }\end{array}$ & $\begin{array}{c}\text { Ensino } \\
\text { Fundamental }\end{array}$ & $\begin{array}{c}\text { Educação de Jovens } \\
\text { e Adultos }\end{array}$ \\
\hline Pesquisa Undime (R\$) & $3.122,40$ & $2.937,70$ & $1.882,00$ \\
Siope (R\$) & $2.195,40$ & $3.047,00$ & 140,10 \\
Diferença nos valores (R\$) & 927,00 & $-109,40$ & $1.741,90$ \\
Diferença percentual (\%) & $-29,7 \%$ & $3,7 \%$ & $-92,6 \%$ \\
\hline
\end{tabular}

Fonte: Banco de dados da pesquisa "Perfil dos gastos educacionais nos municípios brasileiros - ano base: 2009" (Undime); Banco de dados Siope 2009 (FNDE). Tabulação própria.

\section{Tabela 5}

Estimativa de valor por aluno das redes municipais por região (2009)

\begin{tabular}{lcccccc}
\hline Etapa/modalidade & $\begin{array}{c}\text { Brasil } \\
\text { (R\$) }\end{array}$ & $\begin{array}{c}\text { Norte } \\
\text { (R\$) }\end{array}$ & $\begin{array}{c}\text { Nordeste } \\
\text { (R\$) }\end{array}$ & $\begin{array}{c}\text { Centro- } \\
\text { Oeste } \\
\text { (R\$) }\end{array}$ & $\begin{array}{c}\text { Sudeste } \\
\text { (R\$) }\end{array}$ & $\begin{array}{c}\text { Sul } \\
\text { (R\$) }\end{array}$ \\
\hline Creche & $5.144,09$ & $*$ & $1.876,89$ & $3.092,80$ & $8.272,43$ & $5.835,42$ \\
Pré-Escola & $2.647,10$ & $1.710,27$ & $1.531,56$ & $2.384,12$ & $3.757,21$ & $4.461,54$ \\
Educação Infantil & $3.122,36$ & $1.801,53$ & $1.605,48$ & $2.563,07$ & $4.971,26$ & $4.688,83$ \\
Séries Iniciais & $2.815,46$ & $2.554,90$ & $1.948,80$ & $3.048,21$ & $3.649,11$ & $3.586,73$ \\
Séries Finais & $3.134,38$ & $2.998,45$ & $2.276,16$ & $3.000,04$ & $4.322,81$ & $3.673,78$ \\
Ensino Fundamental & $2.937,65$ & $2.676,69$ & $2.034,89$ & $2.987,51$ & $3.897,77$ & $3.582,99$ \\
EJA & $1.881,95$ & $*$ & $1.075,83$ & $2.417,91$ & $2.778,52$ & $2.369,89$ \\
\hline
\end{tabular}

Fonte: Banco de dados da pesquisa "Perfil dos gastos educacionais nos municípios brasileiros - ano base: 2009" (Undime).

\section{Tabela 6}

Fatores de ponderação identificados pela pesquisa - Brasil (2009)

\begin{tabular}{lcc}
\hline Etapa/ Modalidade & $\begin{array}{c}\text { Valor } \\
(\mathbf{R} \$)\end{array}$ & Ponderação \\
\hline Creche & $5.144,09$ & 1,83 \\
Pré-escola & $2.647,10$ & 0,94 \\
Educação Infantil & $3.122,36$ & 1,11 \\
Séries Iniciais & $2.815,46$ & 1 \\
Séries Finais & $3.134,38$ & 1,11 \\
Ensino Fundamental & $2.937,65$ & 1,04 \\
Educação de Jovens e Adultos (EJA) & $1.881,95$ & 0,67 \\
\hline
\end{tabular}

Fonte: Banco de dados da pesquisa "Perfil dos gastos educacionais nos municípios brasileiros - ano base: 2009" (Undime). 


\section{Tabela 7}

Diferença entre fatores de ponderação - Brasil (2009)

\section{Etapa e Modalidade Pesquisa Undime}

1,83

0,94

1

1,11

0,67
Fundeb 2009

Fundeb 2011
1,2

1,0

1

1

1,1

0,8

Fonte: Portaria do Ministério da Educação n. 932, de 30 de julho de 2008; Portaria do Ministério da Educação n. 873, de 1ํ de julho de 2010; Banco de dados da pesquisa "Perfil dos gastos educacionais nos municípios brasileiros - ano base: 2009" (Undime).

\section{Gráfico 1}

Diferença entre valor por aluno em estados selecionados - 2009

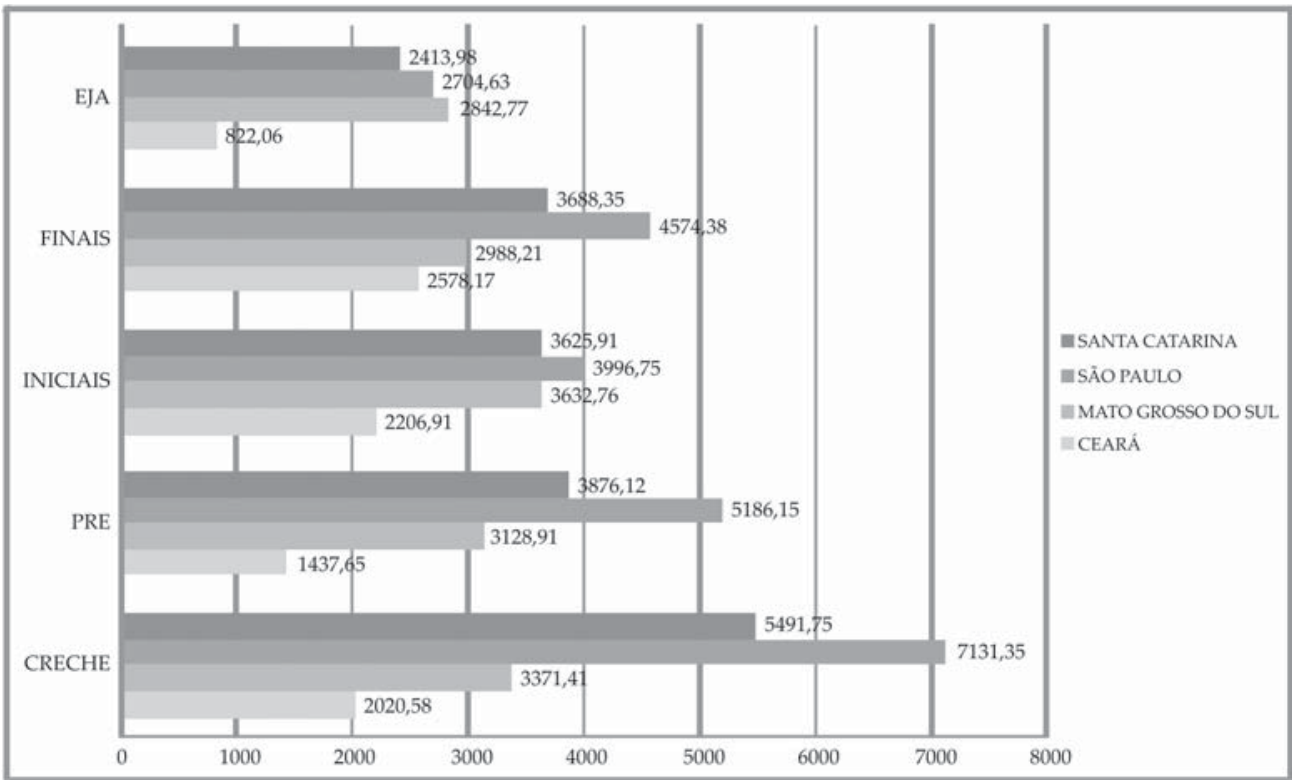

Fonte: Banco de dados da pesquisa "Perfil dos gastos educacionais nos municípios brasileiros - ano base: 2009" (Undime). 


\section{Tabela 8}

Distância percentual entre valores por aluno de Creche em estados selecionados: Fundeb versus Pesquisa - 2009

\begin{tabular}{lcc} 
Estados selecionados & Fundeb 2009 & Pesquisa Undime \\
\hline Ceará & 1 & 1 \\
Mato Grosso do Sul & 1,51 & 1,67 \\
São Paulo & 1,61 & 3,53 \\
Santa Catarina & 1,31 & 2,72 \\
\hline
\end{tabular}

Fonte: Banco de dados da pesquisa "Perfil dos gastos educacionais nos municípios brasileiros - ano base: 2009" (Undime).

\section{Gráfico 2}

Percentual de cobertura do Fundeb dos valores efetivados em creches nos estados selecionados - 2009

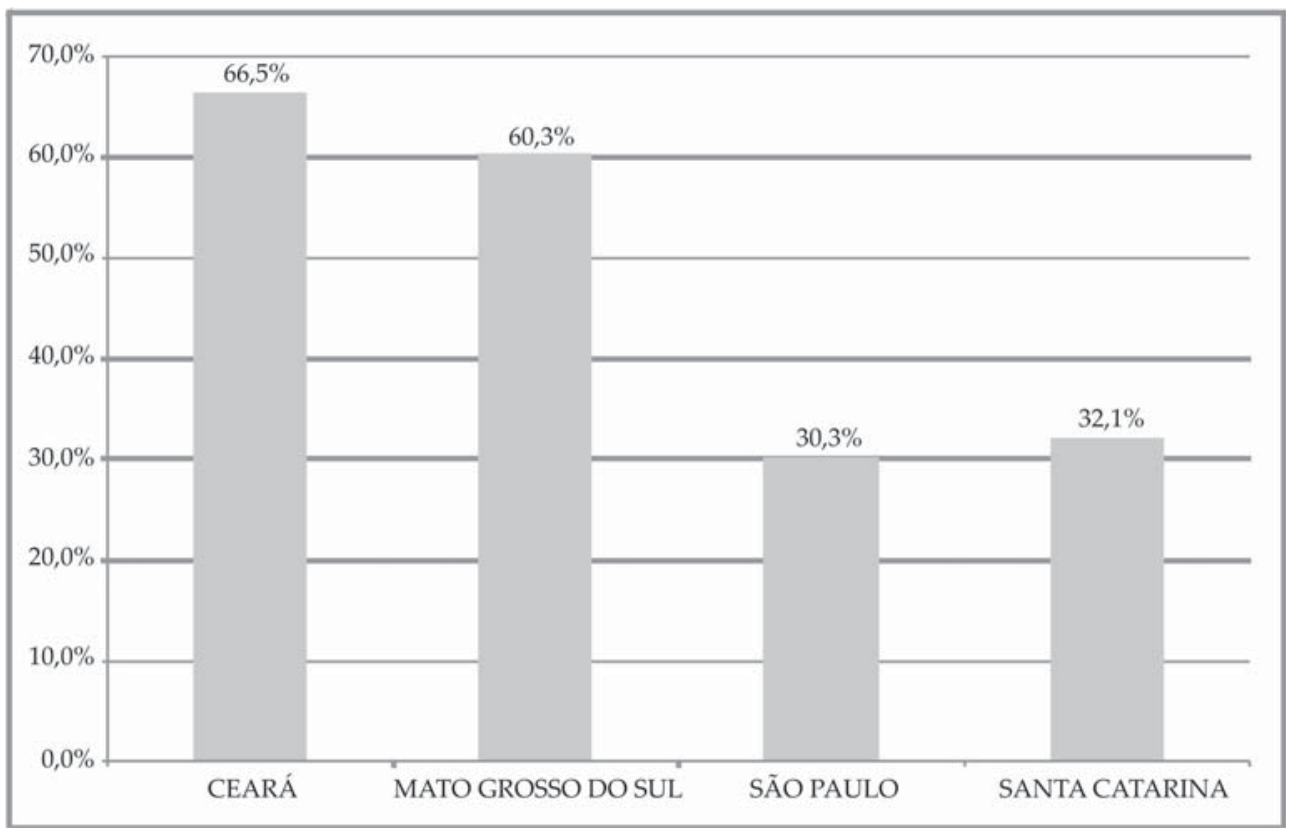

Fonte: Banco de dados da pesquisa "Perfil dos gastos educacionais nos municípios brasileiros - ano base: 2009" (Undime). 
Tabela 9

Comparação entre a região Nordeste e o Parecer CAQi - 2009

\begin{tabular}{lccc}
\hline Etapa e Modalidade & $\begin{array}{c}\text { Pesq. Undime (A) } \\
\text { (R\$) }\end{array}$ & $\begin{array}{c}\text { Parecer CAQi (B) } \\
\text { (R\$) }\end{array}$ & $\begin{array}{c}\text { Diferença (A/ B) } \\
(\mathbf{\%})\end{array}$ \\
\hline Creche & $1.876,89$ & $6.450,70$ & $29,1 \%$ \\
Pré-Escola & $1.531,56$ & $2.527,76$ & $60,6 \%$ \\
Séries Iniciais & $1.948,80$ & $2.396,44$ & $81,3 \%$ \\
Séries Finais & $2.276,16$ & $2.347,20$ & $97 \%$
\end{tabular}

Fonte: Banco de dados da pesquisa "Perfil dos Gastos Educacionais nos Municípios Brasileiros - Ano base: 2009" (Undime); Parecer n. 8/ 2010, da Câmara de Educação Básica do Conselho Nacional de Educação. 